\title{
Oral Health Awareness Among Non Teaching Staff of A Dental Institution in Dakshina Kannada
}

\author{
Shetty MS', Bhat $\mathbf{V}^{2}$, Shenoy $\mathrm{KK}^{3}$
}

\begin{abstract}
OBJECTIVE: The non teaching staff in dental college is indirectly a part of the community based oral health awareness programmes. They act as a link between the dentist and the general population. The objectives of the study is to assess the oral health awareness among non teaching staff in the institution and to utilize the data obtained as a training program for the non-teaching staff and as a baseline for further community based oral health awareness programmes.
\end{abstract}

METHOD: A written oral health questionnaire was developed and distributed to 150 non-teaching staff in a health institution. The data was analysed using SPSS-10 statistical software.

RESULT and CONCLUSION: The staff demonstrated reasonable knowledge, but some deficiencies were noted. The deficiencies in their knowledge could be addressed through the provision of appropriate training and engaging them in improving the oral health and quality of life.

Keywords: Denture cleansing, Dental prosthesis, Oral hygiene habits, Oral status, Self care practices.

${ }^{1} \mathrm{MDS}$

Reader

Department of Prosthodontics

Yenepoya Dental College,Deralkatte,

Mangalore,Karnataka, INDIA

${ }^{2}$ MDS

Professor

Department of Prosthodontics

Yenepoya Dental College,Deralkatte,

Mangalore,Karnataka, INDIA

${ }^{3}$ MDS

Professor

Department of Prosthodontics

Yenepoya Dental College,Deralkatte,

Mangalore,Karnataka, INDIA

\section{Contact Author \\ Dr.Mallika S Shetty mallika_msshetty@yahoo.com \\ J Oral Health Comm Dent 2014;8(2)76-78}

\section{INTRODUCTION}

$\mathrm{K}$

nowledge of oral health is considered to be an essential behaviour. The standard of health of the oral and related tissues enables an individual to eat, speak or socialize without active disease, discomfort or embarrassment and which contributes to overall well being $(1,2)$.The non teaching staff in dental college (staff nurses, receptionists laboratory technicians, attenders and the house keeping staff) are indirectly a part of the community based oral health awareness programmes. They act as a link between the dentist and the general population. They are frequently exposed to the dental procedures and dental materials by either being assistants or spectators. The awareness that they imbibe within the college premises can be shared among their family or in their locality. The patients are more comfortable in approaching the nursing staff to comprehend the instructions given by the dentist. Fearful and anxious patients often approach the same before having their consultation with the dentist. This gives them some basic knowledge regarding oral health and diseases. After the dental treatment the non-teaching staffs explain the after care in the local dialect which makes it easier for the patients to follow. Oral health care has been shown to have low priority in personnel with minimal education (3). However insufficient data is available that can shed light regarding the oral health awareness among the non teaching staff.

\section{MATERIALS AND METHOD}

The study involved completion of a pre-designed questionnaire containing 

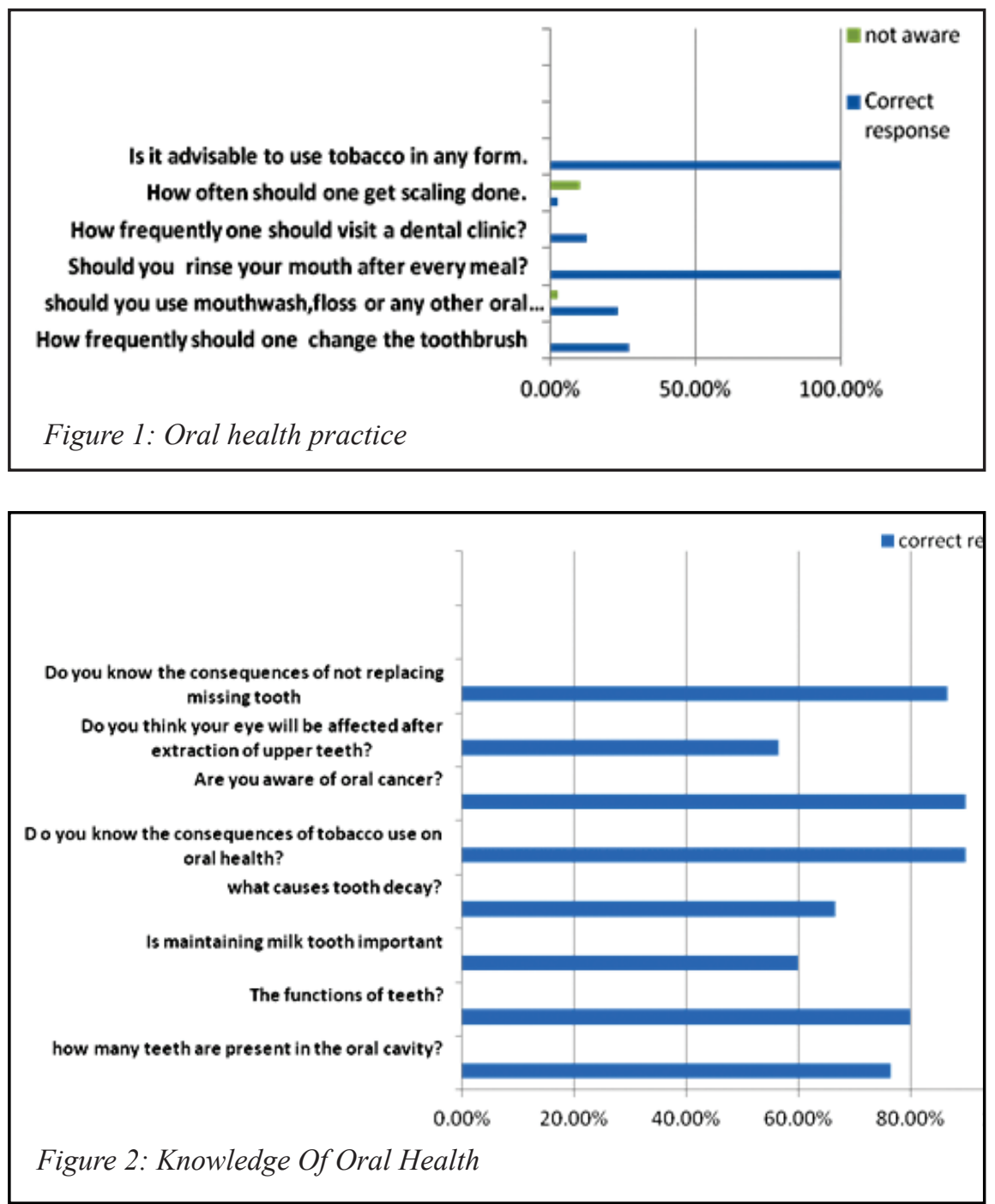

26 variables. Ethical committee clearance was obtained from the university. There are 150 support staff (including staff nurses, receptionists, laboratory technicians, attenders and the house keeping staff) in the institution and they formed the study sample.

The questionnaire was designed to elicit staff's knowledge regarding their attitudes towards dental care, oral health practice, knowledge of oral health and the treatment options. Informed consent was obtained from all the non teaching staff in the institution and they were individually interviewed and explained in local language for ease of understanding. Their responses were recorded and analysed statistically.

\section{Data analysis}

Data collected were entered and the analysis was done using SPSS-10 statistical software.

\section{RESULTS AND DISCUSSION}

According to oral health practices (Figure 1), only $60 \%$ of the subjects brushed their teeth twice daily. This is considerably lower compared with studies in other countries, which showed that between $75 \%$ and $89 \%$ of adults brush twice a day $(4,5)$.

$27.3 \%$ changed their tooth brush once in 3 months, $28 \%$ changed the tooth brush once in 6 months and $44.7 \%$ changed the tooth brush when the bristles flared. $23.3 \%$ of subjects used mouthwash, floss. $2.6 \%$ were not aware of the oral hygiene aids. All the subjects rinsed their mouth after every meal .Majority of the participants (84\%) used toothpicks regularly. All were aware that it is not advisable to use tobacco in any form. $12.6 \%$ visited the dental clinic once in 6 months, $5 \%$ of subjects never visited a dental clinic. Dental caries was the most common cause for the visit. $87.4 \%$ put off visiting the dentist till they encountered a dental problem, which co-relates with a study by Kawamura $\mathrm{M}$ et al, comparing the general nursing students with dental hygiene students (6). Only $2.6 \%$ were aware of frequency of scaling.

Assessment of knowledge of oral health (Figure 2) showed that tooth decay was perceived to be mainly caused by frequent intake of sticky foods $(66.6 \%)$ and least by chewing gum (33.4\%).

$76.6 \%$ were aware of the total number of teeth present in the oral cavity. About the primary functions of teeth $80 \%$ of subjects said teeth are used for chewing, $15 \%$ said for appearance and $5 \%$ said for speaking. $60 \%$ felt that maintaining milk tooth is important, but $40 \%$ felt that it is not important as they will fall off and permanent teeth will erupt and fill the space. $90 \%$ were aware of the consequences of tobacco use on oral health and oral cancer. $56.6 \%$ of subjects has a misconception that their eye will be affected following extraction. $86.6 \%$ know the consequences of not replacing missing tooth.

When assessing attitude towards dental care (Figure 3), 75.33\% knew that scaling does not cause any harm to teeth and periodontium, whereas the rest felt that scaling may cause chipping and loosening of the teeth, sensitivity and gum damage. $54.6 \%$ have missing teeth and only $16 \%$ have replaced them. $61.33 \%$ have decayed teeth., only $17.33 \%$ have restored them. The remaining subjects who have not restored their teeth have either time constraints $(40.8 \%)$ or a few postpone 


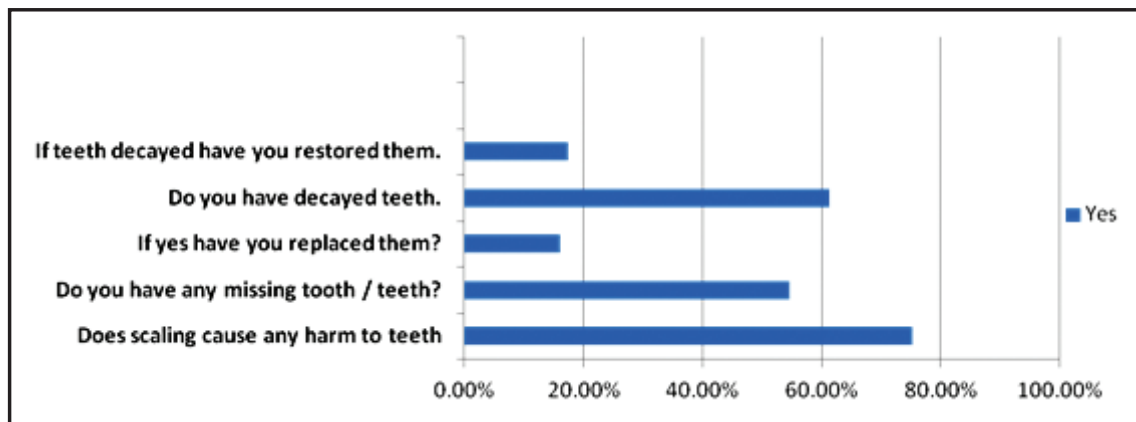

Figure 3: Attitudes Towards Dental Care

with pain being the most common fear factor $(13.8 \%)$. This is in accordance with the study by Mohammad Sami Ahmad et al (7). Only $28.07 \%$ did not find it important to restore their teeth.

\section{CONCLUSION}

This study provides valuable information on the knowledge of oral health of non-teaching staff. The staff nurses demonstrated reasonable knowledge, but some deficiencies were noted. The deficiencies in their knowledge could be addressed through the provision of appropriate training and engage the staff nurses and the other non-teaching staff in improving the oral health and quality of life of their own, their family and the community.

As Dental practitioners we must provide practical and theoretical support to non teaching staff so that they are able to perform their duties better. Further studies can then be carried out to determine the effect of this program.

\section{REFERENCES}

I. Fitzpatrick J. Oral health care needs of dependent older people responsibilities of nurses and care staff . Journal of Advanced Nursing 2000;32(6):1325-32.

2. Hilary T, Mun LW, Holy K. The dental awarenesss of nursing home staff in Singapore a pilot study. Gerodontology 2007;24:58-63.

3. Wardh I, Hallberg LR, Berggren U, et al. Oral health education for nursing personnel experiences among specially trained oral care aids; O ne year follow up interview with oral care aide at a nursing facilty. Scand J Caring 2003;17:250-56.

4. Zeedyk MS, Longbottom C, Pitts NB. Tooth-brushing practices of parents and toddlers: A study of home-based videotaped sessions. Caries Res 2005;39:27-33.

5. Aunger R. Tooth brushing as routine behavior. Int Dent J 2007;57:364-76.

6. Kawamura M, Ikeda-Nakaoka Y, Sasahara H. An assesement of oral self care level among Japanese Dental hygiene students and general nursing students using the Hiroshima UniversityDental Behavior Inventory (HU-DBI). Eur J Dent Edu. 2000;4(2):82-88.

7. Mohammad Sami Ahmad, Ahmed Bhayat, Khalid H Al-Samadani, et al. Oral health knowledge and practice among administrative staff at Taibah university, Madina, KSA 2013;2(3):308-11. 